\title{
O estilo em psicanálise: o discurso do analista como arte do bem dizer ${ }^{1}$
}

\author{
Diego Diz Ferreira*, Rafael Justino da Silva, Christiane Carrijo \\ Universidade Estadual Paulista "Julho de Mesquita Filho" - UNESP, Bauru, SP, Brasil
}

Resumo: $O$ presente artigo circunscreve sua problemática na relação entre campo estético e os processos de subjetivação; de forma mais específica, objetiva analisar os possíveis efeitos estilísticos do discurso psicanalítico na subjetividade, tanto daquele que o pronuncia, como de quem o escuta. Para tanto, toma a análise, discurso do analista sistematizado por Lacan, como estratégia para compreender a questão do estilo em psicanálise. Desvelando a estrutura do discurso analítico, entendido como discurso do analista, é possível identificar que, pela via do estilo, emerge a possibilidade de inscrição do objeto $a$, como marca do real na ordem simbólica regida pela falta.

Palavras-chaves: psicanálise, estilo, arte do bem dizer, objeto $a$.

\section{Introdução}

O que é esse algo que nos encanta, incomoda e por vezes nos angustia no discurso do analista? $\mathrm{O}$ interesse desse breve ensaio é pensar o efeito desse elemento inusitado do discurso do analista, desvelando o que o torna diferenciado do discurso universitário e de outras formações discursivas. Qual seria sua lógica? Como opera seu efeito?

Ao pensar sobre sua lógica, devemos iniciar dizendo que a lógica aprendida na experiência psicanalítica não segue a estruturação clássica dos ditames da lógica formal, situando-se entre o campo estético e os processos de subjetivação. Quando Lacan (1970/1992) sistematiza $O$ avesso da Psicanálise, evidencia o funcionamento lógico de determinados significantes operando nas construções discursivas da cultura e desvela os possíveis efeitos estilísticos do discurso psicanalítico na subjetividade.

A via que assumimos para nos aproximar desses efeitos é a construção de um ensaio fundamentado na análise do discurso do analista, para a qual as contribuições de Lacan são decisivas e somam-se a de outros debatedores. Contudo, não subtraímos do escrito aquele dizer aprendido na experiência analítica, um dizer autoral, construído com o Outro.

Se aprendemos que o estilo é ratificado por uma singularidade, a via estilística torna-se um campo para a dimensão criativa do saber-fazer com as palavras, via pela qual o sujeito goza a impossibilidade do tudo não poder falar. Trata-se de uma estratégia estética assumida por um sujeito que reconhece que a ordem simbólica é marcada pela falta, e, por isso, posiciona-se de forma a bem dizer aquilo que não se pode dizer por completo. Estratégia as-

1 Agradecimentos ao grupo acadêmico de pesquisa do CNPq Psicanálise: Clínica, Teoria e Cultura, ao grupo de extensão Seminários de Psicanálise e Saraus Artísticos e à FAPESP, bem como a todos os docentes que contribuíram com um pouco de seu estilo para a elaboração desse ensaio.

* E-mail para correspondência: diego_dizf@hotmail.com sumida para driblar a castração, ou gozo fálico de dizer aquilo que não pode ser falado, mas pode ser anunciado?

\section{O Discurso do Analista: Ciência ou Arte?}

O empreendimento de sistematização da psicanálise operado por Lacan e a aproximação dessa com a antropologia e linguística estrutural, permitiu compreender que a essência do comunicar-se com o inconsciente é o não se fazer compreender. Existe uma lacuna entre o dito e o dizer: o par significante-significado não apresenta uma correlação fixa e inequívoca; pelo contrário, o que marca a dinâmica entre os elementos linguísticos é a não identidade que lhes é inescapável. Por isso, Lacan (1970/ 1992) dirá que o estilo é a única coisa cabível de se transmitir em uma experiência psicanalítica. É por ele que se suporta a impossibilidade do tudo compreender.

A constatação dessa impossibilidade é o que diferencia a psicanálise de outras áreas do saber; além de teorizar sobre a castração simbólica, a psicanálise a opera em seu regimento lógico. A aproximação com as propostas estruturais permitiu compreender e transmitir de forma mais sistematizada o funcionamento do discurso analítico. Se com o estruturalismo aprendemos que o inconsciente segue um princípio métrico, é estruturado como uma linguagem (Lacan, 1966/1998), seguimos dizendo que é uma linguagem poética. Como em toda poesia existe uma métrica, uma lógica estrutural, assim também é com o inconsciente. Entretanto, tal reconhecimento não significaria um compromisso com o tudo saber; o que se reconhece é que a estrutura é não toda.

Aproximar o discurso do analista com o campo estético é, sobretudo, o esforço de evidenciar a distinção entre essa e outras discursividades, como a religiosa, a filosófica - entendida em sua pretensão de criar sistemas - ou 
a científica. Dizer, entretanto, que o discurso do analista não é o cientifico comporta alguns desafios, principalmente quando nosso olhar é direcionado para a base freudiana.

Freud, ao ingressar na aventura de uma análise psicanalítica da cultura, amplamente conhecida em textos culturais como O Futuro de uma ilusão (1927/1969a) O mal estar na civilização (1930/1969) e Moisés e o monoteísmo (1939/1969c), estaria propondo uma visão de mundo, uma lente investigativa a ser aplicada no humano? Se a psicanálise tem sobre o divã o sujeito cartesiano, o que se formula é um saber sobre tal sujeito. Seria esse um saber da ordem de uma Weltanschauung?

Em Novas conferências introdutórias sobre Psicanálise, Freud (1933/1969d) opera um processo curioso ao falar sobre a questão de uma Weltanschauung. Aproxima a psicanálise da ciência e distancia essa do predicativo de ser uma Weltanschauung, representada principalmente pela religião e teorias como o marxismo: "Os escritos de Marx assumiram o lugar da Bíblia e do Alcorão, como fontes de revelação, embora não parecessem estar mais isentos de contradições e obscuridades do que esses antigos livros sagrados" (Freud, 1933/1969d, p. 175). Todavia, a crítica freudiana retorna ao corpo conceitual da psicanálise seguindo a mesma estruturação, como uma espécie de bumerangue. Os falsificacionistas, como indica Chalmers (1983/2010), não tardaram a alegar ser a psicanálise, assim como o marxismo, uma cosmovisão com pretensões científicas, mas fadada ao insucesso.

Além disso, é notório perceber que Freud faz suas análises culturais centrado nos conhecimentos sobre o inconsciente infantil, e mesmo se diferenciando da opinião dominante de uma supremacia dos processos conscientes sobre o inconsciente, apresenta suas teorias sociais em consonância com a doutrina positivista em voga. É amplamente conhecido que grande parte das críticas feitas a Freud em seu estudo cultural referem-se, principalmente, à sua análise antropológica progressista que aproximava a psicanálise à ciência da época e à formulação de enunciados universalizantes, que deveriam ser utilizados por antropólogos, psicólogos da religião e linguistas como modelos explicativos do fenômeno social.

Contudo, o embrolho entre psicanálise e ciência não constitui o tema dessa investigação; o que se deve notar é que na epistemologia do texto freudiano existe um nítido movimento pendular que ora aproxima a psicanálise da ciência, ora as distancia. Tal estratégia é assumida por Freud pela busca de legitimidade de seu método e foi, antes de tudo, uma saída encontrada por ele para distanciar a psicanálise do ocultismo (Roudinesco, 2000). Tal saída teve consequências e se faz notar nos debates contemporâneos entre Psicanálise e Filosofia da Ciência, apresentando-se como um corolário desse sintoma histórico.

Por isso, é fundamental explicitar a diferença entre discurso do analista e de um outro discurso com pretensões à universalização. A partir de Lacan fica mais fácil compreender que, por ser ratificado em uma singularidade, o discurso do analista carrega a impossibilidade de ser iden- tificado com os atributos e pretensões do método cientifico, devendo estar mais próximo de uma arte, uma estética do discurso.

Uma psicanálise compreendida sob o mote do discurso do analista operaria a distinção entre saber científico, religioso e analítico, uma vez que esse último não visaria dar conta do Real, não escamotearia a falta, mas a colocaria em evidência. Como articula Lacan (1998) em A ciência e a Verdade, existe um paradoxo epistêmico, pois a psicanálise destina seu método investigativo e sua terapêutica ao sujeito da ciência. Falar, portanto, de um discurso do analista e não um discurso analítico demarca a psicanálise como um saber não edificado na suposta neutralidade e imparcialidade do método científico, mas em um desejo, que por vezes nem conhecido é.

Apesar de Freud (1933/1969d) aproximar a psicanálise das ciências naturais, dizendo ser a arte "quase sempre inócua ... não sendo mais nada que uma ilusão" (p. 157), seguimos nos posicionando de que se a psicanálise poderia preterir para si um domínio como o da religião, o cientifico, o filosófico ou o artístico, a escolha mais acertada seria a última. Essa ainda é uma das poucas que se esquiva de suturar o sujeito, remendar as falhas de seu saber. Vivemos em uma época em que ciência e Weltanschauung são praticamente sinônimos.

Entendemos que é pela via do ato artístico criativo que o discurso do analista encontra sua melhor metáfora. A enunciação do analista, assim como a obra de arte, teria o efeito de produzir fascínio ao mesmo tempo em que produz um significante que interroga (Betts, 2006). Aproximar o discurso do analista com a experiência estética seria, portanto, apostar que essa é capaz de modificar o lugar da enunciação do sujeito.

\section{Estilo e Objeto a: Arte do Bem Dizer}

O desejo por formulações e tentativas de sistematizar o saber freudiano conduz Lacan a construir ferramentas de ensino. A instrumentalização dos matemas postulados na teoria dos quatro discursos de Lacan (1970/1992) permite visualizar a dinâmica dos vários elementos (significante mestre: S1; saber: S2; sujeito barrado: \$ e o objeto mais de gozar: a). A figura 1 ilustra a representação dos matemas dos quatro discursos, explicitando que em cada alternância de elementos implica o funcionamento de uma outra lógica. Aqui, nosso interesse restringe-se ao aspecto estrutural do discurso do analista e de suas alternâncias, sobretudo dando ênfase ao lugar ocupado pelo objeto $a$, objeto causa do desejo que faz menção ao real.

\begin{tabular}{cc}
\hline Discurso do Mestre & Discurso Universitário \\
$\frac{\mathrm{S}_{1}}{\$} \rightarrow \frac{\mathrm{S}_{2}}{a}$ & $\frac{\mathrm{S}_{2}}{\mathrm{~S}_{1}} \rightarrow \frac{a}{\$}$ \\
\hline Discurso da Histérica & Discurso Analista \\
$\frac{\$}{a} \rightarrow \frac{\mathrm{S}_{1}}{\mathrm{~S}_{2}}$ & $\frac{a}{\mathrm{~S}_{2}} \rightarrow \frac{\$}{\mathrm{~S}_{1}}$ \\
\hline
\end{tabular}

Figura 1: Os matemas dos quatro discursos 
Neste recurso esquemático visualizamos que os lugares são fixos (figura 2), os elementos que transitam sobre tais lugares que se dinamizam. No discurso do analista é o objeto a que está no lugar de agente. Tal constatação implica necessariamente uma questão de estilo, uma vez que o estilo do analista assenta em um fazer semblante de a.

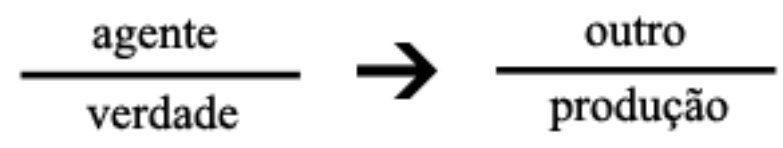

Figura 2: Os lugares do discurso

A circulação do objeto a nos matemas discursivos tem consequências importantes, como inaugurar uma nova lógica na qual um novo tipo de conhecimento é produzido. Quando Lacan (1974/1993) associa a verdadeira forma de se fazer ciência ao discurso da histérica e não à estrutura do discurso da universidade, no qual o lugar de agente já está ocupado pelo saber, demarca a necessidade da produção do saber fundamentar-se no reconhecimento da castração e, portanto, quem deve estar no lugar de agente do discurso é o sujeito barrado (\$). Nota-se assim que ensinar psicanálise ou arriscar-se em um ensino sobre o inconsciente deve por coerência ser um ensino não apenas sobre o inconsciente, mas também com o inconsciente.

A lógica estrutural nos permite visualizar esse "mapa pedagógico", na qual o ensino da psicanálise, em termos de formação acadêmica, só seria então viável por uma combinação entre discurso histérico e discurso analítico. Ensiná-la na lógica do mestre ou do universitário corresponderia a uma tentativa de ser agente de um saber e não apresentar-se como objeto causa do saber. Comprometido com essa causa, Lacan, em seu retorno a Freud, afirma que é apenas pelo estilo que se pode transmitir algo para aqueles que desejam ser psicanalistas (Lacan, 1966/1998). Com isso, inaugura-se um papel decisivo do estilo na transmissão do discurso analítico. Estilo esse que vem do Outro, mas constitui-se como marca da singularidade do sujeito, seu ponto de amarração.

Este saber fazer com as palavras do Outro que estamos chamando de estilo, na construção lacaniana, articula-se veemente ao constructo objeto $a$. Lacan irá desarticular a relação entre estilo e homem, como fazia o filósofo e escritor Buffon, fazendo do estilo a dimensão do real que resiste à ordem simbólica (Lacan, 1966/1998), e não aquilo incorporado do outro em termos de uma pessoalidade imaginária.

O objeto a ocupando o lugar de agente do discurso possibilita um ato de puro dizer. Nas palavras de Quinet (2009), o matema do discurso do analista aparece como “depuração máxima do estilo, pois ele aparece como pura enunciação, sem sentido e até sem significante, no rechaço do discurso" (p. 177). Assim, o estilo do analista faz parecer que a verdade provém do real: como um estilete, ele fura, penetra, corta, rompe com a repetição da cadeia, trazendo o inusitado e provocando assim novas organizações. Mas como se dá tal processo em um tratamento conduzido pela discursividade do analista? Como esse objeto mais de gozar se inscreve?

É sempre bom iniciar tal elucidação partindo de um ponto bem conhecido, mas nem sempre verificável: o de que o Sujeito Suposto Saber é antes de tudo um lugar. $\mathrm{O}$ bom analista reconhece que esse é um lugar transitório e que ser semblante de a só torna-se possível quando o analista desloca-se dessa posição, dada pelo analisando na transferência, em um movimento de "des-ser", que por sua vez é inevitável, ficando-lhe apenas o lugar de resto. Como o analista ocupa um papel nessa passagem na fantasia do analisando, se seu narcisismo não tiver ainda sido encarado, o analista pode custar a sair desse lugar, afinal, o "resto" nem sempre cheira bem.

O processo de queda do sujeito suposto saber - o analista - seria o equivalente a uma castração simbólica para o paciente, possibilitando o acesso ao resto da operação da transferência - lugar do desejo (a). Simbolicamente, a castração corresponde à queda do pai e, assim, permite ao analisante ultrapassá-lo.

E é sob a via do estilo do analista que tal passagem torna-se possível. Analista e analisante desempenham papéis, o primeiro renunciando a seu narcisismo e o segundo identificando-se como o lugar de suposto saber. O estilo, como recurso nessa passagem, torna-se mais que isso, é correlato ao objeto $a$, sendo aquilo que escapa da ordem simbólica, ou seja, é a marca não significante que o analista traz em seu ato. Ato esse que se sustenta pela transferência (Víctora, 2006) e se efetua somente pela linguagem (Lacan, 1967/1968). O analista suporta a transferência e nela oferece a si próprio ao analisante, podendo, dessa maneira, ser incluído na cadeia significante discursiva.

No discurso do analista, o saber aparece no lugar de verdade (Figura 1), indicando que trata-se de um discurso marcado pelo saber, um saber lidar com a castração; assim o estilo, via anunciação, torna-se presente no Ato analítico. Víctora (2006), estudando o Seminário 15: O Ato Analítico ( Lacan, 1967/1968), escreveu sobre o objeto a:

O ponto de chegada seria o lugar de "eclipse", o vazio central que dá lugar ao desejo (a) como resto da operação de transferência. Só aí o sujeito se afirmaria como sujeito do desejo. Note-se que Lacan acrescentou também neste lugar do objeto $a, 0$ - $\varphi$ (menos fi), ao que tudo indica representando a castração simbólica. Em outros seminários, a castração simbólica seria representada pelo $\Phi$ (fi maiúsculo) - o Phallus, que seria o organizador da rede linguística para o sujeito da neurose; sendo que o $\varphi$ (menos fi, minúsculo) seria reservado à castração imaginária, que busca ser preenchida pelas chamadas "insígnias fálicas" do poder, da aparência, etc. Esta separação a/- $\varphi$ será trabalhada mais adiante, como consequência de um final de análise. (p. 06). 
No Seminário 15, Lacan (citado por Betts, 2006), relaciona o ato analítico com a palavra e com o corte, sendo a primeira um significante representante do sujeito e o segundo, representando uma função, o vazio. Lacan descreve a diferença entre o mestre e o escravo, falando da diferença que existe entre ato e fazer e endossando que há os que se ocupam do ato e os que se ocupam do fazer. Como já foi dito anteriormente, o ato analítico é sustentado pela transferência e sustentá-la é suportar ser semblante do objeto $a$ do analisante: "isto quer dizer que o psicanalista não é todo o objeto a, (mas que) ele opera como objeto a" (Betts, 2006, p. 15).

Entende-se o fazer semblante de a como instituir uma ordem do bem dizer, permitindo que pela via do estilo algo da dimensão do real apareça em cena. Tal via é aquela pela qual a dimensão do inapreensível se faz notar; assumindo a posição de agente como objeto $a$, o discurso do analista ganha sua dimensão poética, não visa produção de sentido, mas apresenta-se como enigma, como palavra poética que conclama o sujeito barrado a dizer algo sobre seu sintoma, a se tornar responsável por sua fala, por seu desejo. Considera que o desejo não pode ser dito diretamente, mas que é dito sempre entre as palavras.

Essa forma de dizer, que chamamos de uma arte do bem dizer, não resguarda uma função estilística que se encerra em si própria, ela conclama ao paciente a produção de seu próprio saber, não ficando este refém do significado do outro. Para tanto, o analista nessa formação discursiva deve ocupar semblante de a, vestígio do real que o simbólico não dá conta de representar, objeto causa do desejo, que quando se articula com o sujeito produz a fantasia $(\$ \diamond \mathrm{a})$.

A função epistêmica da psicanálise, originada na experiência clínica, ou, se preferirmos, na ficção de análise, é a possibilidade de criarmos um ambiente que, pela legitimação do inconsciente por parte da figura do analista e de um método livre associativo, possibilita a radical experiência do sujeito deparar com a falta de seu discurso, com a inconsistência de sua criação de sentido, fazendo-o se ver diante da falta constituinte que seu discurso neurótico tenta constantemente escamotear. Finalizar uma análise é, antes de tudo, operar uma mudança de estilo. Trata-se, portanto, de assumir uma nova posição, um estilo marcado pela não necessidade de criar sentido, pela não necessidade de se autoexplicar, uma formação discursiva que, por ratificar-se na ausência, apresenta-se como possibilidade.

O discurso do analista não se limita a um setting preconcebido, mas se faz presente onde existir linguagem. Esse fazer-se presente orientado pela lógica do objeto a é arte do bem dizer, operando no discurso social como estratagema estilístico capaz de orientar os processos de subjetivação, não apenas em nível clínico, mas, sobretudo, no âmbito da cultura.

\section{Considerações finais}

A arte do bem dizer, que convida o inefável a se fazer ouvir nas entrelinhas do discurso, é a tarefa que cabe ao analista. Seu estilo é o que o proporcionará viver essa experiência, é por ele que emerge a possibilidade de inscrição do objeto $a$ na ordem simbólica, conferindo ao discurso do analista sua especificidade.

Entende-se que o estilo não é a palavra, mas trata-se do impronunciável, o indecifrável que se apresenta sobre o deslizar do discurso e, em sua função poética, não se destina a ser apenas recurso retórico ou barroquismo discursivo; é a via pela qual se torna possível suportar a angústia frente à impossibilidade de tudo dizer.

O discurso do analista, preocupado mais em seu como dizer do que com o que dizer, inaugura uma estética na qual a estrutura do discurso tem prevalência sobre aquilo que é falado, que é determinado pelo significante. Tal estética, anunciadora da ordem significante, visaria não apenas a produção de um dito espirituoso encerrado em si, mas também a produção de uma reorganização da fantasia do sujeito, um desestabilizar as convicções imaginárias do neurótico. Mais que uma técnica, o campo estético do discurso do analista, apresenta-se como uma política interventiva que se dá não apenas no sujeito que se espanta ao ingressar nessa discursividade, mas também para aquele portador de tal função.

Encontrar o estilo é tarefa sempre inacabada; implica a necessidade de reunir todos os outros, de se ver diante do Outro, decodificar todas as falas recebidas. Sem que percebamos, essas mensagens difusas desses vários outros vão nos constituindo em um rebotalho chamado Sujeito. Cabe assim àquele que deseja ingressar na arte do bem dizer a depuração de um estilo, uma via de se fazer ouvir na impossibilidade de dizer.

Sendo mais de gozar, o estilo não deve ser copiado. Aqui devemos lembrar o controverso jargão lacaniano "Façam como eu, não me imitem." O que se impõe ao psicanalista é fazer da via do estilo a singularidade de seu ato, implicando que todo ato analítico é um ato criativo, ou seja, trata-se de cada um encontrar sua via, sua poesia, a maneira mais singular de saber fazer com a metonímia; encontrar esse caminho é ser psicanalista. 


\section{The stylistic dimension of psychoanalytic discourse: The art of saying well}

Abstract: This article circumscribes its problem as concerning the relationship between the aesthetical field and the subjectivation processes; more specifically it aims to analyze the possible stylistic effects of the psychoanalytical discourse on the subjectivity of both speaker and listener. To do so, it takes the analysis of the analyst's discourse, systemized by Lacan as a strategy to understand the matter of style in psychoanalysis. Unveiling the structure of the analytical discourse, understood as the analyst's discourse, it is possible to identify that, through style, emerges the possibility of inscription of the object a, as a mark of the real on the symbolical order reigned by loss.

Keywords: psychoanalysis, style, art of saying well, object $a$.

\section{Le style en psychanalyse: le discours de l'annaliste dans l'art du bien dire}

Résumé: Cet article délimite sa problématique dans la relation entre le champ esthétique et les processus de subjectivation; de manière plus spécifique, cet article a pour objectif d'analyser les possibles effets stylistiques du discours psychanalytique dans la subjectivité, aussi bien par ceux qui le prononce, que de ceux qui l'écoute. De ce fait, l'analyse du discours analytique systématisé par Lacan est considéré comme une stratégie afin de comprendre la question de style en psychanalise. Dévoilant la structure du discours analytique, compris comme le discours de l'annaliste, il est possible d'identifier que par la voie du style, emmerge la possibilité de description de l'objet a, comme une marque de la réalité dans l'ordre symbolique régit par la faute.

Mots-clés: psychanalise, style, art du bien dire, objet $a$.

\section{El estilo en psicoanalisis: el discurso del analista como arte del bien decir}

Resumen: Este artículo circunscribe su problemática a la relación entre la estética y los procesos de subjetivación, más específicamente, objetiva analizar los posibles efectos del estilo del discurso en la subjetividad, tanto del que habla como de quien escucha. Para eso, toma el análisis del discurso analítico sistematizado por Lacan como uma estrategia para la comprensión de la cuestión del estilo en el psicoanálisis. Revelando la estructura, del discurso analítico entendida como discurso del analista, es posible identificar que a través del estilo, surge la posibilidad de inscripción del objeto a, como una señal de lo real en el orden simbólico regido por la falta.

Palabras clave: psicoanálisis, estilo, arte de bien decir, objeto $a$.

\section{Referências}

Betts, J. (2006). Ato analítico, ato religioso e ato de criação artística. Correio da APPOA, 149, 13-16.

Chalmers, A. (2010). O que é ciência afinal? São Paulo, SP: Brasiliense. (Trabalho original publicado em 1983)

Freud, S. (1969a). O futuro de uma ilusão. In S. Freud, Edição standard brasileira das obras psicológicas completas de Sigmund Freud (J. Salomão, trad., Vol. 21, pp. 15-63). Rio de Janeiro,RJ: Imago. (Trabalho original publicado em 1927)

Freud, S. (1969b). O mal estar na civilização. In S. Freud, Edição standard brasileira das obras psicológicas completas de Sigmund Freud (J. Salomão, trad., Vol. 21, pp. 67-148). Rio de Janeiro, RJ: Imago. (Trabalho original publicado em 1930)

Freud, S. (1969c). Moisés e o monoteísmo. In S. Freud, Edição standard brasileira das obras psicológicas completas de Sigmund Freud (J. Salomão, trad., Vol. 23). Rio de Janeiro, RJ: Imago. (Trabalho original publicado em 1939)
Freud, S. (1969d). Novas conferências introdutórias sobre psicanálise. In S. Freud, Edição standard brasileira das obras psicológicas completas de Sigmund Freud (J. Salomão, trad., Vol. 22, pp. 155-177). Rio de Janeiro, RJ: Imago. (Trabalho original publicado em 1933)

Lacan, J. (1967/1968). O seminário. Livro 15: o ato analítico. Trabalho não publicado.

Lacan, J. (1992). O seminário. Livro 17: o avesso da psicanálise. Rio de Janeiro, RJ: Jorge Zahar. (Trabalho original publicado em 1970)

Lacan, J. (1993). Televisão, Rio de Janeiro, RJ: Jorge Zahar. (Trabalho original publicado em 1974)

Lacan, J. (1998). Escritos. Rio de Janeiro, RJ: Jorge Zahar. (Trabalho original publicado em 1966)

Quinnet, A. (2009). A estranheza da psicanálise: a Escola de Lacan e seus analistas. Rio de Janeiro: Jorge Zahar.

Roudinesco. E. (2000). Por que a psicanálise? Rio de Janeiro, RJ: Jorge Zahar. 
Víctora, L. (2006). A lógica do ato psicanalítico. Correio da

Recebido: $25 / 06 / 2013$ APPOA, 149, 4-12.

Aceito: $18 / 12 / 2013$ 